\title{
Topographic Guidance in Melt-Electrowritten Tubular Scaffolds Enhances Engineered Kidney Tubule Performance
}

Citation for published version (APA):

van Genderen, A. M., Jansen, K., Kristen, M., van Duijn, J., Li, Y., Schuurmans, C. C. L., Malda, J., Vermonden, T., Jansen, J., Masereeuw, R., \& Castilho, M. (2021). Topographic Guidance in Melt-Electrowritten Tubular Scaffolds Enhances Engineered Kidney Tubule Performance. Frontiers in Bioengineering and Biotechnology, 8, [617364]. https://doi.org/10.3389/fbioe.2020.617364

DOI:

10.3389/fbioe.2020.617364

Document status and date:

Published: 18/01/2021

Document Version:

Publisher's PDF, also known as Version of Record (includes final page, issue and volume numbers)

Please check the document version of this publication:

- A submitted manuscript is the version of the article upon submission and before peer-review. There can be important differences between the submitted version and the official published version of record. People interested in the research are advised to contact the author for the final version of the publication, or visit the $\mathrm{DOI}$ to the publisher's website.

- The final author version and the galley proof are versions of the publication after peer review.

- The final published version features the final layout of the paper including the volume, issue and page numbers.

Link to publication

\section{General rights}

Copyright and moral rights for the publications made accessible in the public portal are retained by the authors and/or other copyright owners and it is a condition of accessing publications that users recognise and abide by the legal requirements associated with these rights.

- Users may download and print one copy of any publication from the public portal for the purpose of private study or research.

- You may not further distribute the material or use it for any profit-making activity or commercial gain

- You may freely distribute the URL identifying the publication in the public portal.

If the publication is distributed under the terms of Article 25fa of the Dutch Copyright Act, indicated by the "Taverne" license above, please follow below link for the End User Agreement:

www.tue.nl/taverne

Take down policy

If you believe that this document breaches copyright please contact us at:

openaccess@tue.nl

providing details and we will investigate your claim. 
OPEN ACCESS

Edited by:

Khoon Lim

University of Otago, Christchurch,

New Zealand

Reviewed by:

Elena M. De-Juan-Pardo,

University of Western

Australia, Australia

Brooke Farrugia,

The University of Melbourne, Australia Tim Dargaville,

Queensland University of

Technology, Australia

*Correspondence:

Miguel Castilho

M.DiasCastilho@umcutrecht.nl

Rosalinde Masereeuw

r.masereeuw@uu.n!

${ }^{+}$These authors have contributed equally to this work

Specialty section:

This article was submitted to

Biomaterials,

a section of the journal

Frontiers in Bioengineering and

Biotechnology

Received: 14 October 2020

Accepted: 16 December 2020

Published: 18 January 2021

Citation:

van Genderen AM, Jansen K Kristen M, van Duijn J, Li Y,

Schuurmans CCL, Malda J,

Vermonden $T$, Jansen J, Masereeuw $R$ and Castilho M (2021) Topographic

Guidance in Melt-Electrowritten Tubular Scaffolds Enhances

Engineered Kidney Tubule Performance.

Front. Bioeng. Biotechnol. 8:617364.

doi: 10.3389/fbioe.2020.617364

\section{Topographic Guidance in} Melt-Electrowritten Tubular Scaffolds Enhances Engineered Kidney Tubule Performance

\author{
Anne Metje van Genderen ${ }^{1 \dagger}$, Katja Jansen ${ }^{1 \dagger}$, Marleen Kristen ${ }^{1,2}$, Joost van Duijn ${ }^{2,3}$, \\ Yang $\mathrm{Li}^{2,3}$, Carl C. L. Schuurmans ${ }^{1,4}$, Jos Malda ${ }^{2,3,5}$, Tina Vermonden ${ }^{3,4}$, Jitske Jansen ${ }^{6}$, \\ Rosalinde Masereeuw ${ }^{1,3 *}$ and Miguel Castilho ${ }^{2,3,7 *}$ \\ ${ }^{1}$ Division of Pharmacology, Utrecht Institute for Pharmaceutical Sciences, Utrecht University, Utrecht, Netherlands, \\ ${ }^{2}$ Department of Orthopaedics, University Medical Center Utrecht, Utrecht University, Utrecht, Netherlands, ${ }^{3}$ Regenerative \\ Medicine Center Utrecht, University Medical Center Utrecht, Utrecht, Netherlands, ${ }^{4}$ Division of Pharmaceutics, Utrecht \\ Institute for Pharmaceutical Sciences, Utrecht University, Utrecht, Netherlands, ${ }^{5}$ Department of Clinical Sciences, Faculty of \\ Veterinary Medicine, Utrecht University, Utrecht, Netherlands, ${ }^{6}$ Department of Pathology and Pediatric Nephrology, Radboud \\ University Medical Center, Radboud Institute for Molecular Life Sciences, Nijmegen, Netherlands, ${ }^{7}$ Department of Biomedical \\ Engineering, Eindhoven University of Technology, Eindhoven, Netherlands
}

Introduction: To date, tubular tissue engineering relies on large, non-porous tubular scaffolds ( $\varnothing>2 \mathrm{~mm}$ ) for mechanical self-support, or smaller ( $\varnothing 150-500 \mu \mathrm{m})$ tubes within bulk hydrogels for studying renal transport phenomena. To advance the engineering of kidney tubules for future implantation, constructs should be both self-supportive and yet small-sized and highly porous. Here, we hypothesize that the fabrication of small-sized porous tubular scaffolds with a highly organized fibrous microstructure by means of melt-electrowriting (MEW) allows the development of self-supported kidney proximal tubules with enhanced properties.

Materials and Methods: A custom-built melt-electrowriting (MEW) device was used to fabricate tubular fibrous scaffolds with small diameter sizes $(\varnothing=0.5,1,3 \mathrm{~mm})$ and well-defined, porous microarchitectures (rhombus, square, and random). Human umbilical vein endothelial cells (HUVEC) and human conditionally immortalized proximal tubular epithelial cells (CIPTEC) were seeded into the tubular scaffolds and tested for monolayer formation, integrity, and organization, as well as for extracellular matrix (ECM) production and renal transport functionality.

Results: Tubular fibrous scaffolds were successfully manufactured by fine control of MEW instrument parameters. A minimum inner diameter of $1 \mathrm{~mm}$ and pore sizes of $0.2 \mathrm{~mm}$ were achieved and used for subsequent cell experiments. While HUVEC were unable to bridge the pores, ciPTEC formed tight monolayers in all scaffold microarchitectures tested. Well-defined rhombus-shaped pores outperformed and facilitated unidirectional cell orientation, increased collagen type IV deposition, and expression of the renal transporters and differentiation markers organic cation transporter 2 (OCT2) and P-glycoprotein (P-gp). 
Discussion and Conclusion: Here, we present smaller diameter engineered kidney tubules with microgeometry-directed cell functionality. Due to the well-organized tubular fiber scaffold microstructure, the tubes are mechanically self-supported, and the self-produced ECM constitutes the only barrier between the inner and outer compartment, facilitating rapid and active solute transport.

Keywords: tissue engineering, melt-electrowriting, bioartificial kidney, contact guidance, 3D culture

\section{INTRODUCTION}

In vivo, cells are surrounded by an extracellular matrix (ECM), a three-dimensional network composed of collagen, glycoproteins, polysaccharides, and other macromolecules (van Genderen et al., 2018). Underneath epithelial and endothelial cells, including renal proximal tubules and peritubular vasculature, the ECM is formed as a thin, highly specialized basement membrane (BM), which acts both as supporting scaffold for the cells, and as barrier between an inner and outer compartment (van Genderen et al., 2018). For kidney tubule engineering, a big challenge is the creation of renal proximal tubules in close proximity to peritubular vasculature. To allow for rapid exchange of solutes between blood and urine, the epithelial and endothelial BM should be virtually the only barriers between both cell types. To date, tubular tissue engineering mostly relies on non-porous, large diameter tubular scaffolds $(\varnothing>2 \mathrm{~mm}$ ) for sufficient selfsupport, or smaller tubular lumens $(\varnothing<1 \mathrm{~mm})$ surrounded by hydrogels to account for physiological functions, including vectorial transport (Homan et al., 2016; Jansen et al., 2017; Rayner et al., 2018; Lin et al., 2019; Singh et al., 2020). The latter has been addressed recently in valuable in vitro tools for drug screening and disease modeling, with proven apical-basal cell polarity, and active reabsorption and transepithelial secretion function. These models provided evidence for the fact that tubular 3D curvature and biomimetic ECM properties enhance kidney cell functionality (Jansen et al., 2015, 2016; Homan et al., 2016; Rayner et al., 2018; Lin et al., 2019; Singh et al., 2020). However, for the engineering of potentially implantable and durable kidney tubules, scaffolds must meet at least three criteria: they must be (1) small-sized and highly porous to increase the surface area, (2) freely accessible from the basolateral and luminal sides for rapid solute exchange and removal, and (3) flexible and yet strong enough to withstand intracorporeal forces such as pressure, tear and wear. Ideally, scaffolds for tubular tissue should also be resorbable and initially provide biophysical instructions to promote cell growth, differentiation, and BM production.

Fibrous scaffold meshes, alone or as reinforcement of hydrogels, can greatly improve the mechanical properties of engineered tissue. At the same time, they can influence cellular functionality and ECM deposition through proper scaffold design. Fibrous scaffolds have shown to facilitate cell migration and functionality by providing physiologically relevant mechanical stimulation (Castilho et al., 2017, 2019; Jansen et al., 2019). For instance, cell growth and growth directionality can be positively affected by microfibers when ordered along a preferential direction (Castilho et al., 2017; Kennedy et al., 2017).
Previously, we provided proof-of-concept for stand-alone $\varnothing<1 \mathrm{~mm}$ kidney tubule grafts fabricated by solution electrospinning (SES), in which human kidney cells were able to bridge considerable fiber-to-fiber distances without the need of embedding hydrogels, which ensured rapid solute uptake (Jansen et al., 2019). Although SES was successful on manufacturing porous tubular fiber scaffolds, this process was rather limited by poor patterning control and hence fabrication reproducibility. Here, we fabricated tubular scaffolds using a superior electrohydrodynamic fiber printing technique called melt electrowriting (MEW) (Brown et al., 2011, 2014). MEW is a solvent-free technique that involves extrusion of a molten polymer fiber onto a computer-controlled collector. Organized 3D tubular constructs are obtained by precise fiber deposition on a rotating cylinder and successive layer-by-layer stacking, which require fine control over instrument parameters, in particular mandrel rotation and translation velocity (Brown et al., 2011; McColl et al., 2018; Robinson et al., 2019). Using MEW, we report the successful fabrication of $\varnothing<1 \mathrm{~mm}$ proximal tubule units that meet all above-mentioned criteria (Figure 1). The first aim was to determine optimal fabrication parameters for $\varnothing=0.5 \mathrm{~mm}$ and $1 \mathrm{~mm}$ tubular scaffolds and to assess their mechanical characteristics. The second aim was to apply these scaffolds to renal epithelial and vascular tubule engineering using conditionally immortalized proximal tubule epithelial cells (ciPTEC) and human umbilical vein endothelial cells (HUVEC); however, only renal epithelial cells were able to form monolayers within the scaffold pores and were used for subsequent experiments. Positive effects of tube structure and biomimetic materials on renal function have already been proven in literature; here, we hypothesized that by engineering tubular scaffolds with defined pore microarchitecture (i.e., rhombus, square and random), we can provide adequate topographic cues to promote cell directionality, autologous BM production, and renal transport function.

\section{MATERIALS AND METHODS}

\section{Melt Electrowriting}

We used a custom-built MEW device consisting of a rotating aluminum mandrel $(\varnothing=3,1,0.5 \mathrm{~mm})$ mounted on a $x-y$ axis and a custom print head mounted of a movable $z$-axis. The $x-y-z$ axes were computer-controlled using an advanced motion controller MC403 (Trio Motion Technology Ltd.). Granular medical grade polycaprolactone (PCL, Purasorb PC 12, Corbion) was loaded into a $3 \mathrm{ml}$ electrically heated glass syringe with a $27 \mathrm{G}$ size metallic nozzle and molten for $30 \mathrm{~min}$ prior printing. The molten 

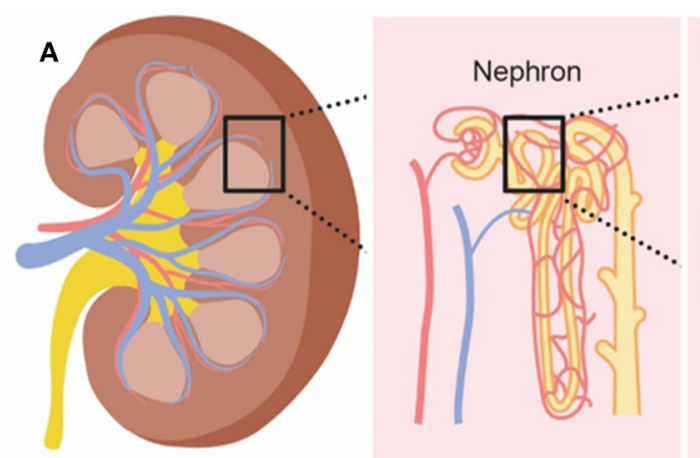

B

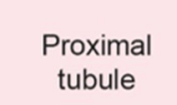

C

Engineered proximal tubule
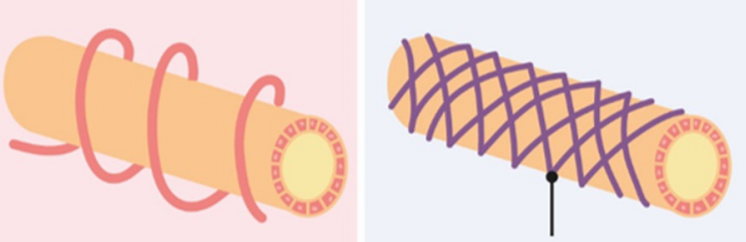

Rhombus scaffold
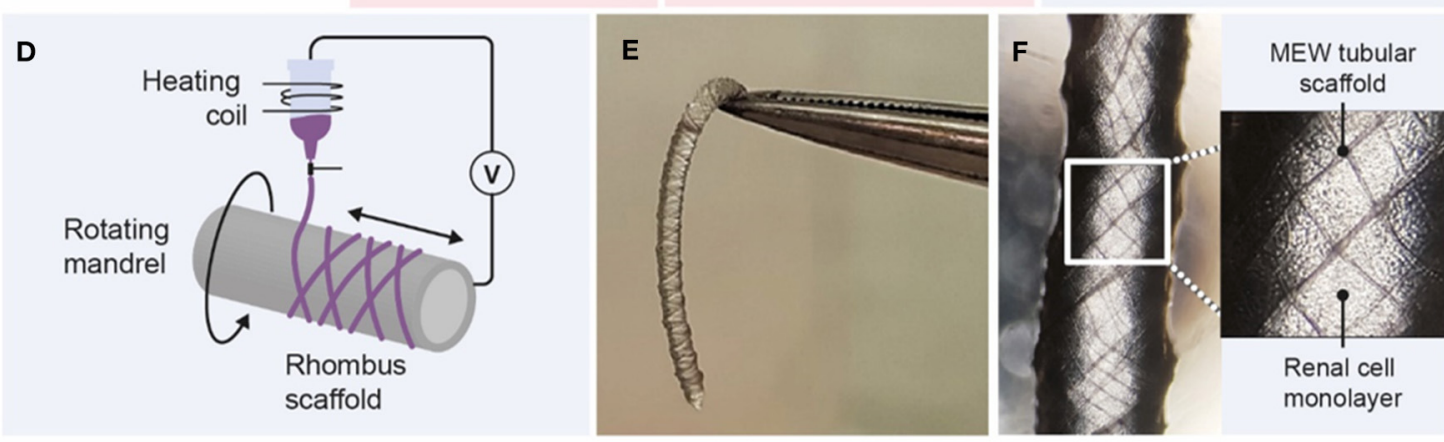

FIGURE 1 | Graphical overview of design and fabrication of MEW medical grade polycaprolactone (PCL) tubular scaffolds. (A) The kidney consists of roughly 1 million functional units, called nephrons. (B) Active secretion takes mostly place in the proximal tubule, which is surrounded by peritubular capillaries. (C,D)

Melt-electrowriting was used to fabricate tubular scaffolds with defined pore geometries. (E,F) Engineered kidney tubules contained confluent monolayers of proximal tubule epithelial cells.

polymer was electrified using a high voltage source (Heinzinger, LNC 30000-5 POS, 0-30 kV), and extrusion was assisted by a high-resolution air pressure regulator (VPPE-3-1-1/8-2-010-E1, Festo). In order to control scaffold microarchitectures, the effect of tangential rotation velocity $\left(\mathrm{V}_{\text {tang }}\right)$ and translation velocity $\left(\mathrm{V}_{\text {trans }}\right)$ on the laydown fiber winding angle $(\alpha)$ was investigated (Supplementary Figure 1). The theoretical winding angle was determined according to,

$$
\alpha=\operatorname{ArcTang}\left(\mathrm{V}_{\text {tang }} / \mathrm{V}_{\text {trans }}\right)
$$

for $0<\alpha<90^{\circ}$. The $V_{\text {tang }}$ expressed in $\mathrm{mm} / \mathrm{s}$ was assessed by,

$$
\mathrm{V}_{\text {tang }}=\pi \mathrm{dV}_{\mathrm{r}}
$$

where $\mathrm{d}$ is the diameter of the collecting mandrel in $\mathrm{mm}$ and $V_{r}$ is the rotational velocity of the mandrel in $\mathrm{rad} / \mathrm{s}$. Both $V_{\text {tang }}$ and $V_{\text {trans }}$ were varied according to specified in Table 1 in order to obtain scaffolds with winding angles of 30 and $45^{\circ}$, corresponding to a square and rhombus microarchitecture, respectively; and a densely distributed crossed fibremat (alternating winding angles between 30,45 , and $60^{\circ}$ ) here named random. The $x-y$ position of the mandrel and respective translational velocity were programmed using a commercially available software package (Motion Perfect V4.2, Trio Motion Technology Ltd.) while the rotational velocity was controlled by Arduino IDE software. The combination of parameters used to obtain the three different scaffold microgeometries and tubular diameters is summarized in Table 1. After fabrication, the mandrel with the printed tubular scaffold was soaked in ethanol for $5 \mathrm{~min}$ to facilitate scaffold removal. As the $0.5 \mathrm{~mm}$ mandrels showed some variation of working distance between the mandrel and the nozzle, $1 \mathrm{~mm}$ tubes were used for the biological experiments.

\section{Imaging and Structural Characterization}

Tubular scaffolds microstructure and fiber size were analyzed by stereomicroscopy (Olympus SZ61) and by scanning electron microscopy (SEM, Phenom Pro, Phenom-World). SEM was performed at an acceleration speed of 5-10 kV. Prior imaging, SEM scaffolds were gold sputtered coated $(1 \mathrm{~nm})$ using a Q150R rotary-pumped sputter (Quorum Technologies). Images from both stereomicroscope and SEM were analyzed with Image J (National Instruments). Scaffold porosity was determined gravimetrically.

\section{Cell Culture}

Human conditionally immortalized proximal tubule epithelial cells (ciPTEC), isolated from human kidney tissue, were developed by Jansen et al. (2014). The tissue used for cell line development was obtained from non-transplanted donors with given informed consent. Briefly, proximal tubule cells obtained from healthy volunteers were infected with a temperature sensitive mutant U19tsA58 of SV40 large T antigen (SV40T) and 
TABLE 1 | Summary of printing parameters used to fabricate melt-electrowritten tubular scaffolds.

\begin{tabular}{|c|c|c|c|c|c|c|c|c|}
\hline Winding angle $\left({ }^{\circ}\right)$ & $\begin{array}{l}\text { Tube diameter } \\
\text { (mm) }\end{array}$ & $\begin{array}{c}\text { Effective } \\
\text { speed }(\mathrm{mm} / \mathrm{s})\end{array}$ & $\begin{array}{c}\text { Tangential } \\
\text { speed, Vtang } \\
(\mathrm{mm} / \mathrm{s})\end{array}$ & $\begin{array}{c}\text { Translational } \\
\text { speed, Vtrans } \\
\text { (mm/s) }\end{array}$ & $\begin{array}{l}\text { High voltage } \\
\text { (kV) }\end{array}$ & $\begin{array}{c}\text { Melting } \\
\text { temperature } \\
\left({ }^{\circ} \mathrm{C}\right)\end{array}$ & $\begin{array}{l}\text { Dispensing } \\
\text { pressure }\end{array}$ & $\begin{array}{c}\text { Collecting } \\
\text { distance }(\mathrm{mm})\end{array}$ \\
\hline \multirow[t]{3}{*}{30} & 0.5 & 3 & 1.5 & 2.6 & 6.5 & 90 & 0.65 & 4 \\
\hline & 1 & 3 & 1.5 & 2.6 & 5.5 & 85 & 1 & 4 \\
\hline & 3 & 3 & 1.5 & 2.6 & 5.0 & 80 & 1 & 4 \\
\hline \multirow[t]{3}{*}{45} & 0.5 & 3 & 2.1 & 2.1 & 6.5 & 90 & 0.65 & 4 \\
\hline & 1 & 3 & 2.1 & 2.1 & 5.5 & 85 & 1 & 4 \\
\hline & 3 & 3 & 2.1 & 2.1 & 5.0 & 80 & 1 & 4 \\
\hline \multirow[t]{3}{*}{60} & 0.5 & 3 & 2.6 & 1.5 & 6.5 & 90 & 0.65 & 4 \\
\hline & 1 & 3 & 2.6 & 1.5 & 5.5 & 85 & 1 & 4 \\
\hline & 3 & 3 & 2.6 & 1.5 & 5.0 & 80 & 1 & 4 \\
\hline
\end{tabular}

the essential catalytic subunit of human telomerase (hTERT). ciPTEC were cultured at $33^{\circ} \mathrm{C}$ and $5 \%(\mathrm{v} / \mathrm{v}) \mathrm{CO}_{2}$ up to $90 \%$ confluency to maintain a cell proliferation state. For maturation, ciPTEC were transferred to $37^{\circ} \mathrm{C}$ for at least 7 days prior to experimental readout. ciPTEC were cultured in T175 cultures flasks (Greiner Bio-One), using Dulbecco's modified eagle medium/HAM's F12 without phenol red (Thermofisher Scientific), supplemented with $5 \mu \mathrm{g} \mathrm{mL}^{-1}$ insulin, $5 \mu \mathrm{g} \mathrm{mL}-1$ transferrin, $5 \mu \mathrm{g} \mathrm{mL}^{-1}$ selenium, $35 \mathrm{ng} \mathrm{mL}^{-1}$ hydrocortisone, 10 ng mL $\mathrm{mL}^{-1}$ epidermal growth factor, $40 \mathrm{pg} \mathrm{mL}^{-1}$ tri-iodothyronine (Sigma-Aldrich), 10\% fetal bovine serum (FBS) (Greiner BioOne), and $1 \%$ penicillin/streptomycin (Thermofisher Scientific). For 2D cultures, ciPTEC were cultured and matured in 6 well plates. Primary human umbilical vein endothelial cells (HUVEC) [American Type Culture Collection (ATCC)] were cultured using vascular cell basal medium and endothelial cell growth kit-VEGF (ATCC). HUVEC were cultured in T175 culture flasks (Greiner Bio-One) at $37^{\circ} \mathrm{C}$ and $5 \%(\mathrm{v} / \mathrm{v}) \mathrm{CO}_{2}$, and confluency was maintained at a maximum of $90 \%$ throughout the culture period.

\section{Scaffold Coating and Cell Seeding Onto Scaffolds}

Before cell seeding, PCL tubular scaffolds were sterilized using $70 \%$ ethanol evaporation and UV exposure $(365 \mathrm{~nm}$ for $15 \mathrm{~min}$ ). $2 \mathrm{mg} / \mathrm{mL} \quad \mathrm{L}-3,4-$ dihydroxyphenylalanine (L-DOPA, Sigma-Aldrich) was dissolved in $10 \mathrm{mM}$ tris(hydroxyethyl)aminomethane (Tris) $\mathrm{pH} \quad 8.5$ buffer at $37^{\circ} \mathrm{C}$ for $45 \mathrm{~min}$ (Ni et al., 2011; Oo et al., 2011; Jansen et al., 2015). After sterile filtration $(0.2 \mu \mathrm{m}$ pore size $)$, scaffolds were coated through submersion for $4 \mathrm{~h}$ at $37^{\circ} \mathrm{C}$ and thoroughly washed with phosphate buffered saline (PBS without calcium and magnesium, Lonza). Next, $10 \times 10^{6}$ cells $/ \mathrm{ml}$ were added in small culture medium drops onto flat scaffolds or injected into tubular scaffolds. Cells were incubated for $4 \mathrm{~h}$ at $33^{\circ} \mathrm{C}$ (ciPTEC) or $37^{\circ} \mathrm{C}$ (HUVEC); tubular scaffolds were turned $180^{\circ}$ after $2 \mathrm{~h}$. Afterwards, culture medium was added, and the constructs were cultured until confluency at $33^{\circ} \mathrm{C}$ and then at $37^{\circ} \mathrm{C}$ (ciPTEC), or directly at $37^{\circ} \mathrm{C}$ (HUVEC). Scaffolds were cultured for $1-4$ weeks at $37^{\circ} \mathrm{C}$. Culture medium was refreshed $3 \mathrm{x}$ per week. Changes on polymer surface wettability before and after L-DOPA coating were evaluated by static contact angle measurements using sessile drop technique (Data Physics, OCA $15 \mathrm{EC})$. Measurements were performed according to a procedure described elsewhere (Castilho et al., 2017).

\section{Immunofluorescence}

Scaffolds were fixed for 5 min with $4 \%(\mathrm{v} / \mathrm{v})$ paraformaldehyde in PBS and permeabilized with $0.3 \%(\mathrm{v} / \mathrm{v})$ triton $\mathrm{X}-100$ in PBS for $10 \mathrm{~min}$ at RT. Subsequently, cells were exposed to blocking buffer consisting of $2 \%(\mathrm{v} / \mathrm{v})$ FCS, $0.5 \%(\mathrm{w} / \mathrm{v})$ bovine serum albumin (BSA), and $0.1 \%(\mathrm{v} / \mathrm{v})$ Tween 20 in PBS for $30 \mathrm{~min}$ at RT. Antibodies were diluted in blocking buffer. Primary antibodies were incubated $\mathrm{O} / \mathrm{N}$ at $4^{\circ} \mathrm{C}$ and secondary antibodies for $1 \mathrm{~h}$ at RT. We used the following primary and secondary antibodies and dilutions: mouse monoclonal anti- $\alpha$-tubulin 1:150 (T6793, Sigma-Aldrich), goat monoclonal anti-collagen IV 1:50 (1340-01, Southern Biotech), and mouse monoclonal anti CD31 1:250 (ab119339, Abcam), AlexaFluor 488 donkey-anti-rabbit 1:200 (Invitrogen), AlexaFluor 488 goatanti-mouse 1:200 (Invitrogen), and AlexaFluor 647 donkeyanti-goat 1:200 (Invitrogen). Moreover, we used AlexaFluor 546 phalloidin 1:1,000 (A22283, Thermo Fisher Scientific) to stain actin filaments, and nuclei were stained using DAPI 1:1,000 (Sigma-Aldrich). Immunofluorescence was examined using confocal microscopy (Leica TCS SP8 X) and software Leica Application Suite X. Images were analyzed using ImageJ. Images were converted to 8-bit, Z-projections were made, and the same threshold was applied for every image. Actin filament directionality was quantified using the directionality functionality and Fourier components analysis.

\section{Gene Expression}

Gene expression analysis was performed by RT-qPCR on ciPTEC after growing at $33^{\circ} \mathrm{C}$ until confluency and 7 days at $37^{\circ} \mathrm{C}$. RNA was isolated from ciPTEC grown in tubular scaffolds or in LDopa coated well plates (control) using a PureLink RNA mini kit (Invitrogen), and cDNA was prepared using $500 \mathrm{ng}$ sample RNA templates using iScript ${ }^{1}$ cDNA Synthesis Kit (BioRad). RT-qPCR analysis was performed on a CFX96 real-time PCR detection system (BioRad) using TaqMan Universal PCR Master

${ }^{1}$ RNA isolation kit that was used for this protocol. 
Mix and TaqMan Gene Expression Assay (Thermo Fisher Scientific) for COL4A1 (TaqMan Assay ID: Hs00266237_m1), ABCG2 (Hs01053790_m1), ABCC4 (Hs00988721_m1), ABCB1 (Hs00184500_m1) and SLC22A2 (Hs00533912_m1), RPS18 (Hs01375212_g1). All reactions were carried out with equivalent dilutions of each cDNA sample.

\section{Mechanical Testing}

The mechanical properties of cell free and cell cultured tubular constructs (day 14 of culture at $37^{\circ} \mathrm{C}$ ) were studied under uniaxial tensile test using a Dynamic Mechanical Analyzer (DMA Q800, TA Instruments). Before testing, cell cultured constructs were washed with HBSS, fixated for $10 \mathrm{~min}$ with $4 \%(\mathrm{v} / \mathrm{v})$ paraformaldehyde and then washed again with HBSS. Tensile tests were performed at a rate of $0.1 \mathrm{~N} / \mathrm{min}$. Prior testing, nominal diameter and length of each construct was measured using stereomicroscopic and SEM images. The tangent modulus, yield strain and elastic strain energy were determined from engineered stress-strain curves. Tangent moduli were determined using a least square fit of the initial slope of the stress-strain elastic region $\left(\mathrm{E}_{\mathrm{T}}\right.$, as presented in Supplementary Figure 3$)$, yield point $\left(\varepsilon_{\mathrm{el}}\right)$ was defined as point where nonlinear deformation begins and elastic strain energy $\left(\mathrm{U}_{0}\right)$ was obtained,

$$
U_{0}=\int_{0}^{\varepsilon_{e l}} \sigma d \varepsilon
$$

where $\sigma$ and $\varepsilon$ represent engineered stress and strain, respectively.

\section{Functional Assays}

To test the functionality of various transporters (BCRP, MRP4, P-gp and OCT2), tubular scaffolds with rhombus-shaped pores and ciPTEC were matured for 3 weeks, rinsed in HBSS, and incubated with fluorescent substrates. Cells were incubated with $1 \mu \mathrm{M}$ non-fluorescent calcein-AM for $15 \mathrm{~min}$ at $37^{\circ} \mathrm{C}$ to confirm cellular metabolism through enzymatic conversion of calcein-AM to fluorescent calcein. Incubation was performed in presence or absence of $5 \mu \mathrm{M} \mathrm{MK}-571$ and KO173 (inhibitors of MRP4 and BCRP) to validate functional excretion of calcein. Moreover, tubular scaffolds were incubated with $10 \mu \mathrm{M}$ rhodamine123 (RH123), substrate for uptake transporter OCT2 and excretion transporter P-gp, in presence or absence of $5 \mu \mathrm{M}$ tetrapentylammonium $\left(\mathrm{TPA}^{+}\right.$, OCT2 inhibitor) or $5 \mu \mathrm{M}$ PSC833 (P-gp inhibitor) for $40 \mathrm{~min}$ at $37^{\circ} \mathrm{C}$. After incubation, the scaffolds were rinsed with HBSS and images were captured with green filters using the Keyence BZ-9000 fluorescence microscope (Keyence). ImageJ (National Instruments) was used to measure fluorescence intensity in 16-bit images after background subtraction. In addition, a leakage assay was performed with rhombus-shaped scaffolds to assess engineered proximal tubule function. First, a customized perfusion chamber was designed and printed with polylactic acid (PLA) using a fused filament fabrication method (Ultimaker). The printed chamber was mounted on a glass slide using epoxy glue (Loctite), and tubular scaffolds were fixed inside with dental glue (GI-MASK Automix, Coltene) (Supplementary Figure 4). Scaffolds were perfused with $0.1 \mathrm{mg} / \mathrm{ml}$ fluorescein isothiocyanate-inulin for
5 min (inulin-FITC, Sigma-Aldrich), and real-time imaged using a fluorescence microscope with a green filter (Keyence BZ-9000).

\section{Statistical Analysis}

Unless otherwise stated, 3 scaffolds per condition were used in 3 independent experiments respectively. Statistical analysis was carried out in Graphpad Prism 8.1.0 (GraphPad Software Inc.) using a student $t$-test when two groups were compared, and a one-way ANOVA and Tukey's multiple comparisons post-hoc test when 3 or more groups were compared. A two-way ANOVA and multiple comparisons were used for comparison of multiple groups with 2 independent variables. Differences were considered significant with a $p$-value of $p<0.05$. ${ }^{*}$ indicates $p<0.05,{ }^{* *} p<$ $0.01,{ }^{* * *} p<0.001$ and ${ }^{* * * *} p<0.0001$. Data are represented as mean \pm standard error of the mean (SEM) or as mean \pm standard deviation (SD).

\section{RESULTS}

\section{Design and Fabrication of Microfibrous Tubular Scaffolds}

Fully resorbable medical grade polycaprolactone (PCL) tubular scaffolds were manufactured with a reproducible quality using an in-house built MEW set-up (Figures 1, 2, Supplementary Movie 1). Scaffolds were fabricated with a range of winding angles, from $30^{\circ}$ to $60^{\circ}$, by controlling the ratio between the tangential rotation velocity $\left(\mathrm{V}_{\text {tang }}\right)$ and the translation velocity $\left(\mathrm{V}_{\text {trans }}\right)$ (Supplementary Figure 1). No significant differences in fiber diameter were observed when varying the winding angle (constant fiber diameter of approximately $20 \mu \mathrm{m}$, Figure $\mathbf{2 A}$ ), and the measured winding angle was in accordance with the theoretical design (Figure 2B). Additionally, the effect of fiber stacking on printed winding angle was evaluated (Figure 2C, Supplementary Figure 2). In general, an increase in the deviation between designed and printed winding angle was observed when increasing the number of staked fibers from 1 to 10 layers. This difference was in average $33 \pm 8$ for $0.5 \mathrm{~mm}$ mandrels (Supplementary Figure 2A) and 7 $\pm 3 \%$ for $3 \mathrm{~mm}$ (Supplementary Figure 2B) and $1 \mathrm{~mm}$ mandrels (Figure 2C). Importantly, our results demonstrate that the fiber diameter did not change significantly when increasing the number of staked layers, as well as when varying the winding angle. Furthermore, while 3 and $1 \mathrm{~mm}$ diameter tubes could be easily removed from the mandrels, harder removal of $0.5 \mathrm{~mm}$ tubes from the mandrel was observed, which compromised their structural integrity. Based on these post-processing handling characteristics and printing fidelity results, tubes with $1 \mathrm{~mm}$ diameter and 10 layers (final thickness of $\sim 100 \mu \mathrm{m}$ ) were selected for further experiments. Tubular scaffold with three different microarchitectures were fabricated, i.e., rhombus (winding angle $30^{\circ}$ ), square (winding angle $45^{\circ}$ ) and random (densely distributed crossed fiber mat, with winding angles varying between 30,45 , and $60^{\circ}$ ). Notably, interconnected porosities above $90 \%$ and controlled pore sizes of $200 \mu \mathrm{m}$ where obtained for rhombus (Figures 2D-F) and square pore shaped scaffolds, while only $40 \%$ porosity were observed for random scaffolds and no controlled pore size (Figure 2D). 


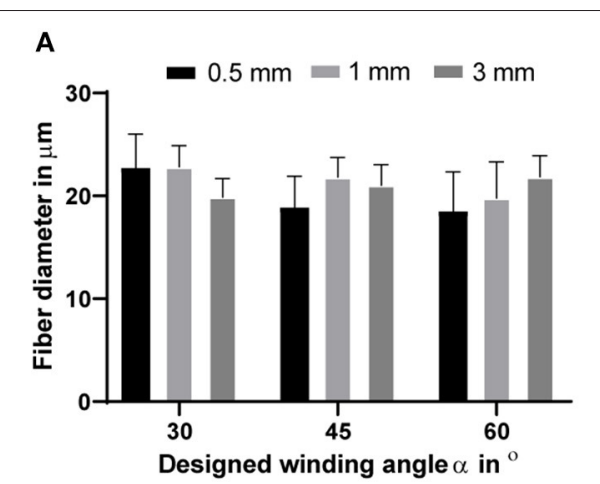

D

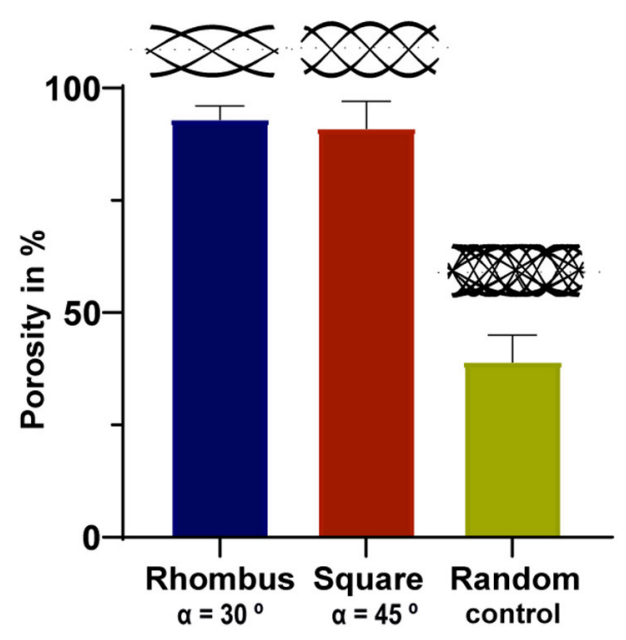

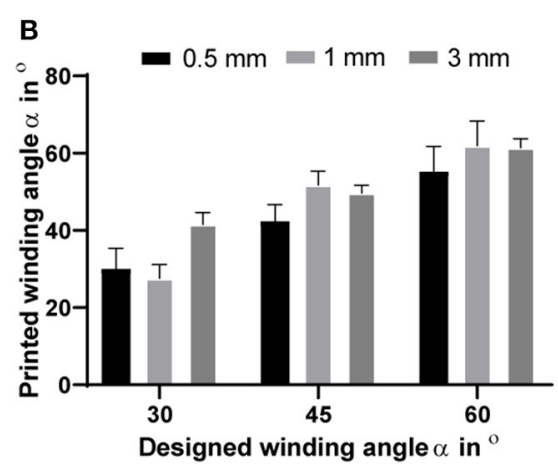

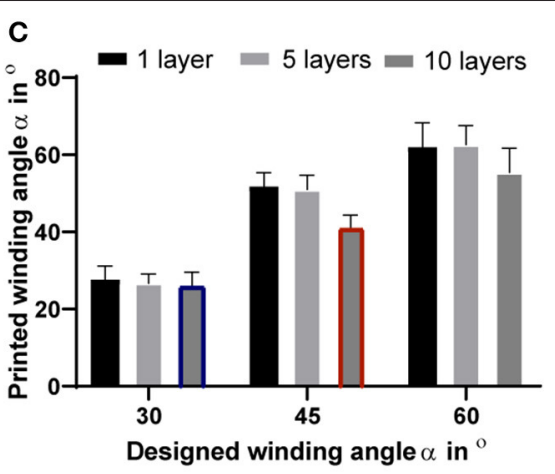

E

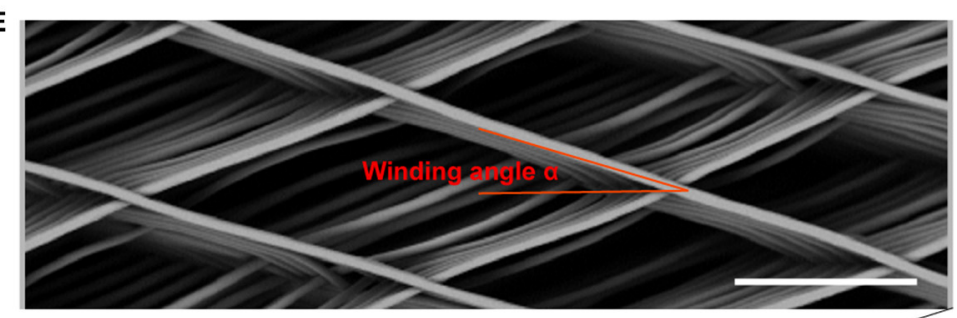

F

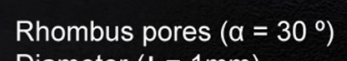

Diameter $(\phi=1 \mathrm{~mm})$

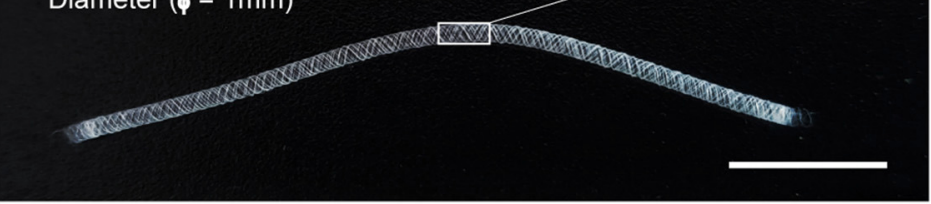

FIGURE 2 | Tubular scaffold design and fabrication. (A) variation of printed fiber diameters according to designed winding angles. (B) Comparison between designed and printed winding angle used to assess printing accuracy. $(\mathbf{A}, \mathbf{B})$ were investigated for constructs with a single layer and for mandrels with three different diameters, 3, 1- and 0.5-mm. (C) Comparison between designed and printed winding angle for constructs with 1, 5 and 10 stacked layers and mandrel with 1 mm in diameter. Blue and red identify rhombus and square constructs used for further mechanical and biological experiments. (D) Porosity of fabricated tubes with 1 mm diameter. Representative (E) stereoscopic and (F) SEM image of printed tubular scaffolds with a rhombus $\left(30^{\circ}\right)$ microstructure for $1 \mathrm{~mm}$ mandrel. Scale bars $=100 \mu \mathrm{m}(\mathbf{E})$ and $1 \mathrm{~cm}(\mathbf{F})$.

\section{Cell Growth and Directionality}

The first requirement of functional bioengineered kidney tubules is cell adherence and growth into a barrier-forming monolayer. Confirming our previous data, ciPTEC were able to form tight monolayers in L-DOPA biofunctionalized tubular scaffolds by stretching across the pores between the PCL microfibers (Jansen et al., 2019). L-DOPA coating increased scaffold hydrophilicity compared to non-coated tubular scaffolds (Supplementary Table 1). Cells grew on the PCL-fibers, then they started bridging the pores from the corners and moved further inward; ultimately, the pores were entirely filled by ciPTEC monolayers. Only at a pore size of $400 \mu \mathrm{m}$ and higher, ciPTEC were not able to bridge the gap.

Cell growth and filamentous actin (F-actin) orientation were studied in scaffolds with rhombus, square and random pore geometries (Figures 3A-I). For HUVEC, no microgeometry allowed monolayer formation; the cells only surrounded the PCL fibers (Figures 3A-C). When stained for platelet endothelial cell adhesion molecule 1 (PECAM-1 or CD31), a marker for endothelial cell junctional integrity, we observed irregular expression (Figures 3A-C). PECAM-1 is only expressed at the cell borders of confluent monolayers, whereas little or no expression is observed in sparse or migrating endothelial cells (RayChaudhury et al., 2001; Privratsky and Newman, 2014). In contrast to HUVEC, ciPTEC were able to fill the pores with all geometries investigated. For ciPTEC, rhombus-shaped pores caused preferential cell alignment along the scaffold fiber direction. The angle of deviation for ciPTEC grown in rhombusshaped pores was approximately $25^{\circ}$, which is in accordance with the $30^{\circ}$ winding angle of the pores, indicating that ciPTEC are aligned as instructed by the geometry. The cell alignment order parameter $S$ was calculated for ciPTEC, where a value of $S=1$ would indicate that the long axis of the cells perfectly aligned with the scaffold fiber direction and $S=0$ indicated no particular cell alignment. CiPTEC grown on rhombus-shaped pores exhibited cell alignment with an $S$ of $0.51 \pm 0.06$, whereas both square and random microgeometries resulted in an isotropic distribution of 

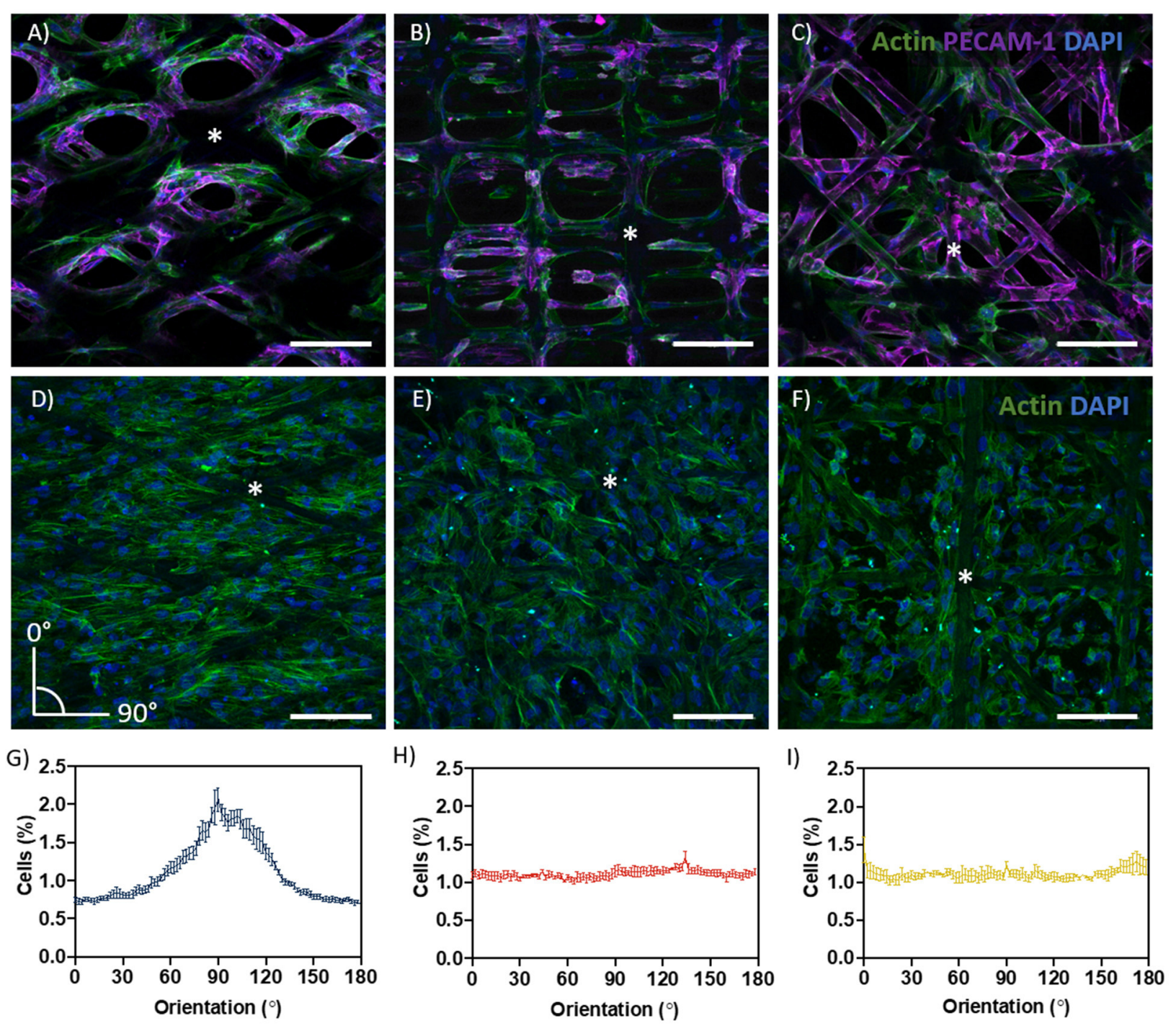

FIGURE 3 | Cell growth and directionality. (A-C) Actin filament (green), PECAM-1 (purple), and DAPI (blue) in (A) rhombus-, (B) square-, and (C) random-shaped scaffolds for HUVEC. (D-F) Actin filament (green) and DAPI (blue) in (D) rhombus-, (E) square- and (F) random-shaped scaffolds for ciPTEC. Asterisks identify fiber scaffold position. (G-I) Quantification of cell directionality in (G) rhombus-, (H) square- and (I) random-shaped scaffolds for ciPTEC. Scale bars $=250 \mu \mathrm{m}$. Mean \pm SEM, $n=3$

cells with order parameters of 0 (Figures 3D-I) (Duclos et al., 2014; Li et al., 2017).

\section{Renal Transporter Expression and Function}

The proximal tubule has a major role in waste secretion from the blood into the urine, and, therefore, expresses a broad range of functional transporters to facilitate this transport. We tested the effect of pore microgeometries on the gene expression of four relevant transporters: the efflux pumps breast cancer resistance protein (BCRP), multidrug resistance-associated protein 4 (MRP4), and P-glycoprotein (P-g), and the uptake transporter organic cation transporter 2 (OCT2). For all microgeometries, mRNA levels were compared to $2 \mathrm{D}$ culture (Figures 4A-D). For BCRP (Figure 4A, CT value 2D: $33.47 \pm 0.12$ ) and MRP4
(Figure 4B, CT value 2D: $29.60 \pm 0.03$ ), no differences were found. Remarkably, mRNA expression for P-gp increased 2.4fold (Figure 4C, $p<0.05$, CT value 2D: $29.43 \pm 0.03$ ) for tubular scaffolds with rhombus-shaped pores compared to $2 \mathrm{D}$ culture. Also, OCT2 expression was 3.4-fold higher (Figure 4D, $p<0.01$, CT value 2D: $37.85 \pm 0.30$ ). In tubular scaffolds with isotropic pore microgeometries, transporter expression showed no significant increase compared to traditional 2D culture. Two functional assays were performed to validate transporter function in rhombus-shaped pores (Figures 4E-J). Calcein-AM diffuses into the cell, where it is hydrolyzed by esterases into fluorescent calcein, which is then secreted by BCRP and MRP4 (Figure 4E) (Caetano-Pinto et al., 2016). When incubating the engineered kidney tubules with calcein-AM in presence of BCRP and MRP4 
A

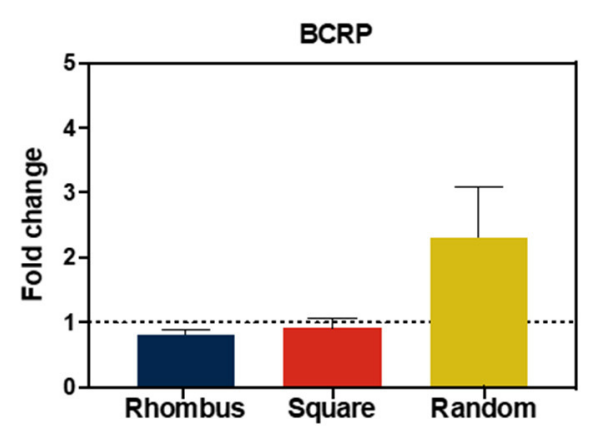

C

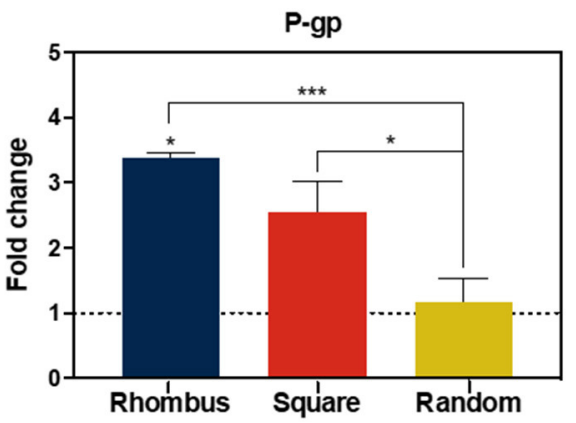

E

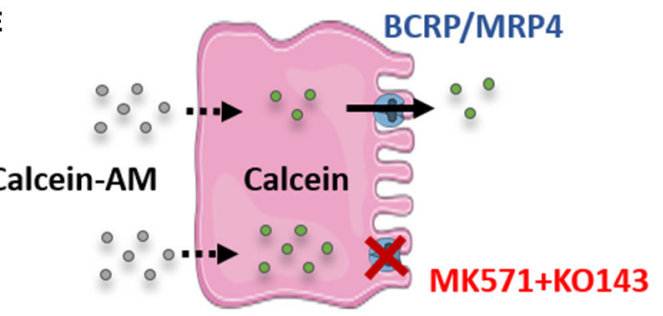

G
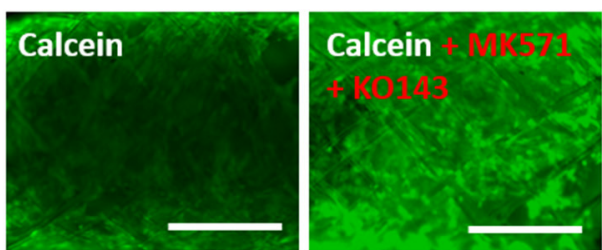

I

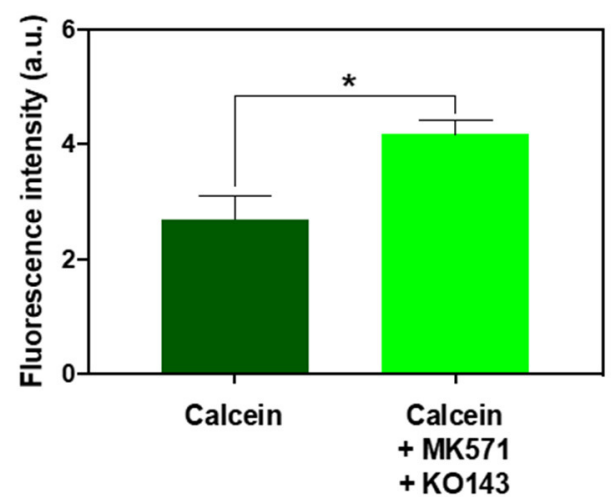

B

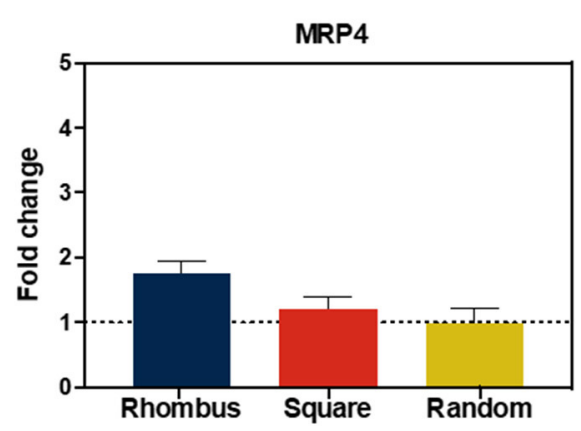

D

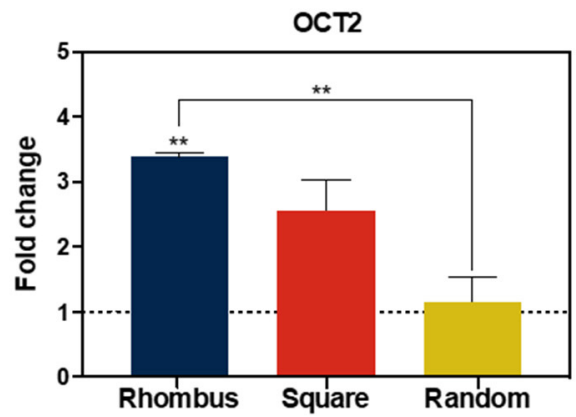

F

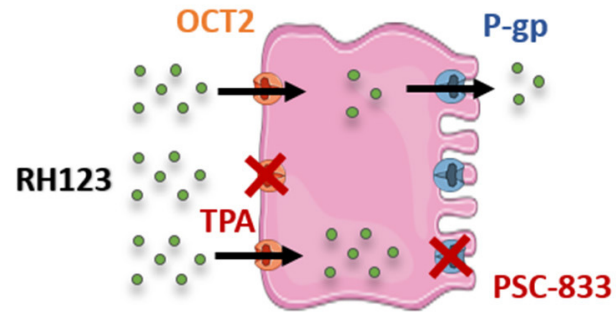

H

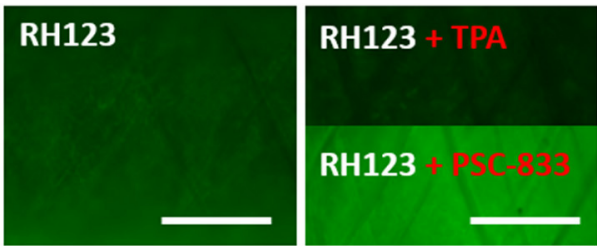

J

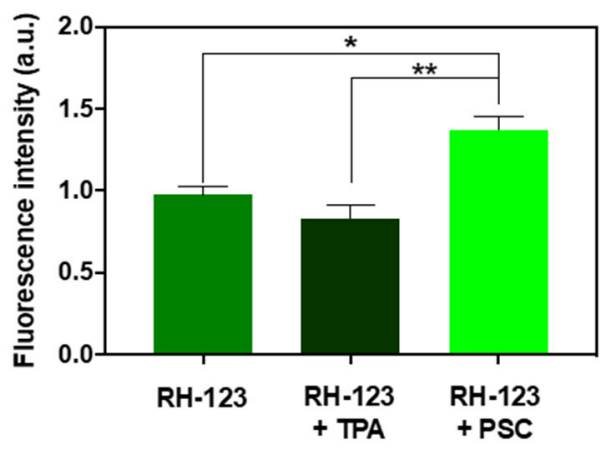

FIGURE 4 | Renal transporter expression and function. (A-D) Relative mRNA gene expression of ciPTEC cultured in tubular scaffolds with rhombus-shaped pores compared to ciPTEC cultured in 2D (dotted line). (E,F) Graphical overview of (E) calcein-AM assay and (F) rhodamine123 assay. (G,H) Immunofluorescent images of (G) calcein-AM assay and (H) rhodamine123 assay in presence or absence of inhibitors. (I,J) Quantification of immunofluorescent images measured as fluorescence intensity for $\mathbf{( I )}$ calcein and $\mathbf{( J )}$ rhodamine123. Scale bars $=500 \mu \mathrm{m}$. Mean $\pm \mathrm{SEM}, n=3 .{ }^{\star} P<0.05 ;{ }^{* \star} P<0.01$; ${ }^{\star \star \star} P<0.001$. 


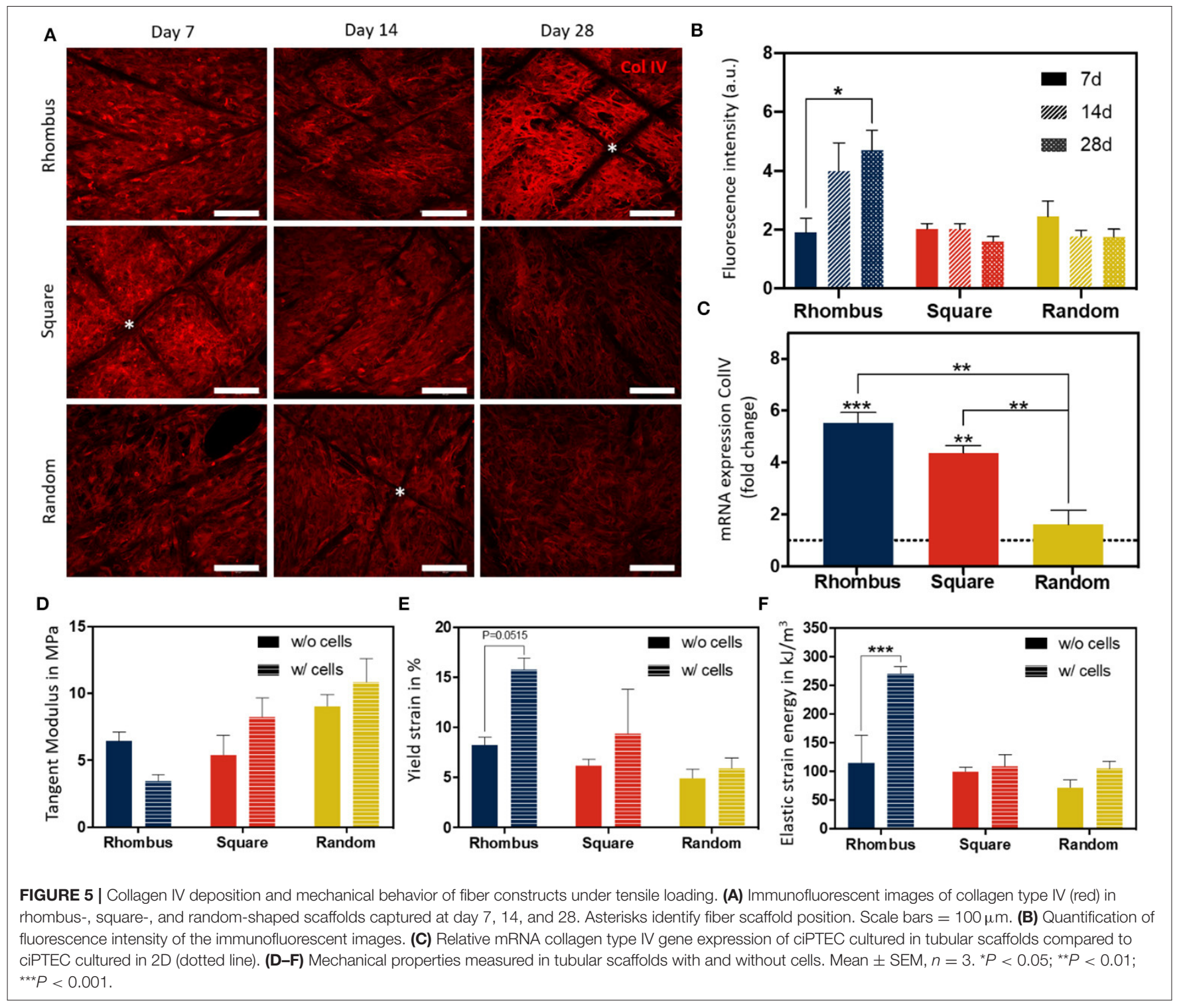

inhibitors KO143 and MK571, calcein accumulated in the cells (Figures 4G,I) $(p<0.05)$. Rhodamine-123 (RH123) is a chemical fluorescent compound that is actively transported into the cell via OCT2 and actively excreted into the urinary compartment by Pgp and BCRP (Figure 4F). When the OCT2 inhibitor TPA was added, RH123 intracellular fluorescence intensity tended to be lower, although not significantly. When the P-gp inhibitor PSC833 was added, intracellular fluorescence intensity increased $(p<$ 0.05) (Figures 4I,J).

\section{Collagen IV Deposition}

Collagen type IV is the most abundant component of the renal $\mathrm{BM}$, making up $50 \%$ or more of the total (van Genderen et al., 2018). To investigate how pore microgeometries affected ECM deposition, collagen type IV expression was measured over time, i.e., at day 7,14 , and 28 , after starting maturation at $37^{\circ} \mathrm{C}$ (Figures 5A,B). In all pore microgeometries tested, ciPTEC deposited collagen type IV and filled all pores at the earliest timepoint measured (day 7). While collagen type IV deposition remained equal over time in random and square microgeometries, it significantly increased $(p<0.05)$ in rhombus scaffolds, with a maximum collagen type IV expression on day 28 (Figure 5B). On mRNA level, collagen type IV expression increased 5.5-fold in rhombus-shaped pores compared to traditional 2D culture at day 7 ( $p<0.001$, CT value $2 \mathrm{D}: 32.46 \pm$ 0.33) (Figure 5C). Square-shaped pores also increased collagen IV mRNA levels in ciPTEC (4.4-fold, $p<0.01$ ), whereas randomshaped pores did not have any beneficial effect compared to 2D cell culture (Figure 5C). Finally, we assessed how cells and their BM affected the mechanical properties of the MEW tubular scaffolds. Engineered kidney tubules were matured for 14 days before they were evaluated under uniaxial tensile loading to determine tangent modulus, yield strain, and elastic strain energy (Figures 5D-F, Supplementary Figure 3). A non-linear stress-strain behavior was observed for the different tested microarchitectures (Supplementary Figure 3). Interestingly, without cells scaffolds with a rhombus geometry were able to reach higher elastic deformations (2-fold higher, approximately 

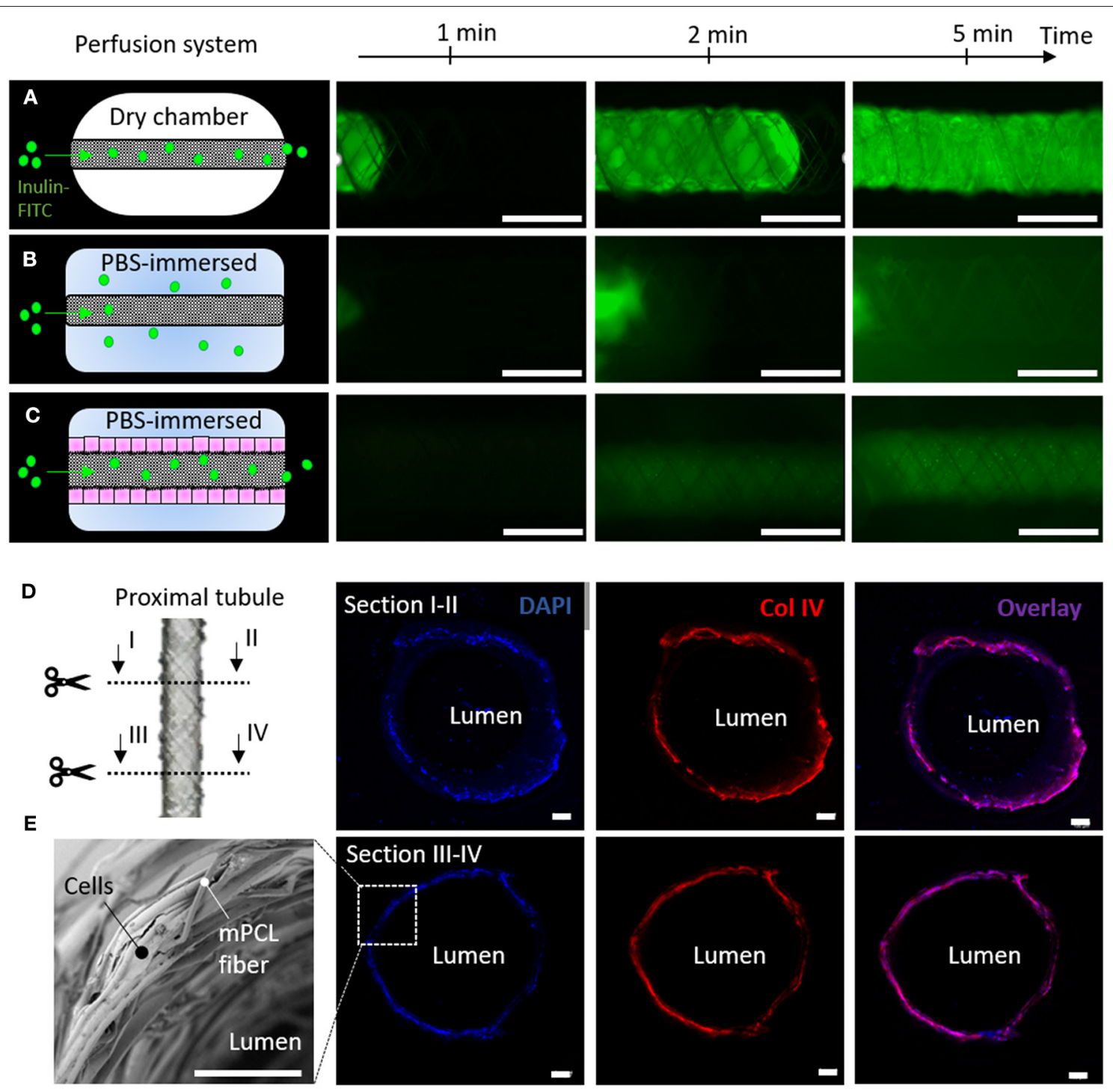

FIGURE 6 | Renal barrier function. (A-C) Inulin-FITC leakage assay in rhombus-shaped tubular scaffolds (A,B) without and (C) with cells. Perfusion chamber (A) dry and (B,C) immersed in PBS. Immunofluorescent images are captured after 1, 2 and 5 min of Inulin-FITC perfusion. (D) Cross-sectional immunofluorescent images indicating a monolayer of ciPTEC throughout the construct. Immunofluorescent staining for DAPI (blue) and collagen type IV (red). (E) Representative SEM image of cell laden rhombus-shaped tubular scaffolds demonstrating a renal monolayer. Scale bars $=100 \mu \mathrm{m}$.

$10 \%$ deformation) and lower tangent modulus (1.7-fold lower, 4 $\mathrm{MPa}$ ) than scaffolds with random microstructure (Figures 5D,E, Supplementary Figure 3). No significant differences were observed on tangent modulus and elastic strain between scaffolds with a squared and random microarchitecture. In tubular scaffolds with ciPTEC monolayers, we observed a trend for an increase in yield strain $(p=0.0515)$ and an increase in elastic strain energy $(p<0.0002)$ in tubules with rhombus-shaped pores compared to scaffolds without cells (2- to 3-fold higher). It should be noted that a promising elastic behavior (shape recovery without visual permeant deformation) was observed for rhombus scaffolds after repetitive manual stretching, not observed for square and random tubular scaffolds (data not shown).

\section{Barrier Function}

In our engineered kidney tubules, cells and their self-made BM deposited within the scaffold pores formed the only barrier between the basolateral and luminal side of the tubes. A thin but tight barrier is crucial for vectorial solute transport. To functionally assess barrier formation, inulin-FITC leakage was measured using a custom-made perfusion system. When mounting cell-free scaffolds in a dry chamber, inulin-FITC remained inside the scaffold due to surface tension (Figure 6A), but when PBS was added to the chamber, inulin-FITC directly leaked out (Figure 6B). In contrast, ciPTEC-laden scaffolds kept the inulin-FITC inside the lumen, indicating that the cells and their BM functioned as a leak-tight barrier between the luminal and basolateral sides of the engineered kidney tubule 
(Figure 6C). Engineered kidney tubules were also stained for collagen type IV and DAPI, and cross-sections were randomly made to confirm monolayer formation throughout the tubular construct (Figures 6D,E). For rapid solute exchange and future implantation purposes, engineered kidney tubules must be flexible, wear-resistant, small in diameter, highly porous, and freely accessible from both the basolateral and luminal side. Using MEW, we fabricated self-supported, highly ordered tubular scaffolds with controlled pore microarchitectures (i.e., rhombus and square). We were able to produce scaffolds with an inner diameter of $0.5 \mathrm{~mm}$, which is around 7 times the diameter of native kidney tubules and only 2 times the diameter of common dialysis fibers. While smaller diameters might be possible in future, the constructs also needed to remain easy to handle for experimental testing. The ability to control tubular scaffold microarchitecture is a unique characteristic of MEW that distinguishes the process from other conventional fiber formation technologies like SES. For kidney tubule engineering, we identified rhombus-shaped pores as a superior microgeometry over square- and random-shaped pores: topographic guidance resulted in directed cell growth, enhanced collagen type IV deposition, remarkably improved yield strain and elastic strain energy, and increased functional OCT2 and P-gp expression.

\section{DISCUSSION}

\section{Rhombus-Shaped Pores Mimic in vivo Renal Tubular Basement Membrane Anisotropy Through Topographic Guidance} In vivo, the renal tubular BM exhibits an anisotropic structure, i.e., a directional preference in form of a polygonal meshwork of corrugated appearance (Hironaka et al., 1993). In contrast to square- and random-shaped pores, rhombus-shaped pores guided cell growth along the scaffold fibers into a preferred cell direction with an angle of deviation that was even smaller than the winding angle of the scaffold. This phenomenon is called contact or topographic guidance (Bourget et al., 2013; Andalib et al., 2016). The effects of various topographic features on ciPTEC have been evaluated previously; already small features $(<5 \mu \mathrm{m})$ could induce cell organization and alignment, which made the cells more susceptible to mechanical cues such as fluid shear stress (FSS) (Frohlich et al., 2012, 2013; Hulshof et al., 2018). The alignment of the actin cytoskeleton might have contributed to the increased BM and transporter gene expression. Importantly, the cytoskeleton reorganization is known to alter force-activated pathways, as well as nuclear actin structures that can regulate gene expression and cell differentiation (Tremblay et al., 2013; Sankaran et al., 2019). Although more research is needed to confirm such underlying mechanisms in renal cells, our data do confirm beneficial effects of anisotropic cues on cell growth behavior and differentiation. The effects of different pore sizes and shapes of MEW scaffolds on cell alignment and gene expression have been shown to vary per cell type, including macrophages, bone marrow, smooth muscle cells, cardiomyocytes, and skeletal stem cells (Castilho et al., 2018; Eichholz and Hoey, 2018; Brennan et al., 2019; Saidy et al., 2019;
Tylek et al., 2020). This indicates that the choice of pore size and shape need to be carefully considered depending on cell type of interest. For HUVEC, it has been shown that topographic cues of ridges and grooves can stabilize the endothelial phenotype. Based on the physiological BM microarchitecture in vivo, alignment in circumferential direction would be preferred (Gasiorowski et al., 2010; Bourget et al., 2013). In our study, HUVEC failed in filling the MEW-fabricated pores of any microgeometry tested. Most likely, HUVEC have a smaller spreading length compared to ciPTEC, which is the only parameter besides initial pore size needed for predictions of void filling (Joly et al., 2013).

\section{Renal Monolayers in MEW Pores Are Freely Accessible for Solute Uptake and Separate Compartments}

Inhibitor-sensitive cellular uptake and excretion of fluorescent compounds demonstrated functional transport activity of our engineered kidney tubules. Vectorial solute transport requires an intact and polarized epithelial monolayer that forms a barrier between the luminal and the outer compartment. Microscopic images revealed consistent monolayer formation throughout the construct, which was confirmed by retainment of inulin-FITC during luminal perfusion. For uptake and subsequent drainage of metabolic waste products, an outside-oriented basolateral side, and an apical membrane facing the lumen are crucial. Usually, the interaction between cells and ECM are a determinant factor in the orientation and stabilization of cell polarity (Chambard et al., 1981). However, freshly seeded cells are not provided with a pre-existent ECM in our scaffolds, thus polarization likely depends on factors other than ECM cues. It is known that fluid shear stress (FSS) can facilitate cell polarization and has moreover been shown to enhance transporter expression in epithelial cells (Jang et al., 2013; Homan et al., 2016; Weber et al., 2016; Vriend et al., 2020). Possibly, FSS could induce polarization and further enhance cellular functionality in our scaffolds, therefore future steps will include the establishment of a long-term flow-compatible cell culture system.

\section{Rhombus-Shaped Pores Increase Yield and Elastic Strain Energy of Engineered Kidney Tubules}

When handled or potentially implanted, engineered kidney tubules should be able to withstand external influences like pressure, tear and friction. When subjected to axial forces, controlled pore microgeometries themselves had a significant effect on tangent modulus, yield strain and elastic energy of tubular scaffolds when compared with non-controlled pore microgeometries. This evidence was even more pronounced when cells formed monolayers within the pores. Kidney tubules with rhombus-shaped pores could sustain higher strain $(\sim 15 \%)$ before yielding compared to random and square $(<10 \%)$, probably due to the contact guided cell alignment with the fiber direction. Compared to tangent moduli of kidney tissue reported in literature $(3-10 \mathrm{MPa})$, the tangent modulus of $4 \mathrm{MPa}$ for the kidney tubules with rhombus-shaped pores (evaluated 14 days after monolayer formation) was close to the lower limit of this range (van Genderen et al., 2018). It should be noted 
that mechanical properties were tested after fixaiont, which tends to increase the tangent modulus (Ling et al., 2016; Kim et al., 2017). However, considering the increase in ECM deposition over the course of 28 days in culture, an overall improvement in mechanical properties can be expected over time. Notably, the control over scaffold microarchitecture on tubular constructs with $1 \mathrm{~mm}$ allowed for aligned ECM deposition and consequent impressive compliance using PCL, a rather stiff thermoplastic material, as scaffolding material. It is important to mention, that future improvement of the MEW process is required to generate tubular scaffolds with tunable mechanical properties and internal diameters below $1 \mathrm{~mm}$ diameter. Recent works have reported the design and melt-electrowriting of auxetic tubular microfibers with unprecedent control of elastic deformations that could be applied in engineered kidney tubules. However, internal diameters obtained were one order of magnitude higher, $10 \mathrm{~mm}$, than the ones reported here (Paxton et al., 2020).

\section{Next Steps Toward Perfusable and Vascularized Engineered Kidney Tubules}

As mentioned above, the establishment of long-term perfusion systems will further advance kidney tubule performance and readouts. Moreover, the flexible nature of MEW tubular scaffolds allows the intertwinement of multiple scaffolds, which would create direct contact between epithelium and endothelium, mimicking the physiological situation (Hironaka et al., 1993; van Genderen et al., 2018). Twisting scaffolds would additionally protect and stabilize the constructs. To engineer peritubular blood vessels, the initial pore size could be reduced by combination of MEW with electrospinning, as shown by Jungst et al. (2019) and Pennings et al. (2019). Furthermore, the use of supportive cell types like pericytes or fibroblasts could help in the formation of endothelial monolayers (Bertlein et al., 2018). In fact, direct contact between different cell types on PCL scaffolds, as opposed to indirect contact, can improve cell functionality (Wang et al., 2015). Also, co-cultures of endothelial cells with renal epithelial cells have been shown to stimulate the balanced expression of various endothelial factors, which in turn improved the performance of renal cells (Tasnim and Zink, 2012).

In conclusion, we report the fabrication of self-supportive and yet small-sized porous MEW tubular scaffolds for kidney tubule engineering. MEW scaffolds enable direct access to the basolateral and luminal cell sides to facilitate solute exchange with vasculature in immediate proximity, which is critical for functional proximal tubule constructs. We showed that rhombus-shaped pores can enhance kidney tubule performance through topographic guidance, highlighting the fact that proper scaffold design offers opportunities to improve cell function.

\section{DATA AVAILABILITY STATEMENT}

The datasets presented in this study can be found in online repositories. The names of the repository/repositories and accession number(s) can be found below: https://doi.org/10. 1101/2020.09.16.300004.

\section{AUTHOR CONTRIBUTIONS}

AG, KJ, JJ, RM, and MC contributed to the conception of this research. AG, KJ, TV, JJ, RM, and MC contributed to the experimental setup. AG, KJ, MK, JD, YL, CS, and MC performed the experimental work and data analysis. AG, KJ, MK, RM, and $\mathrm{MC}$ wrote the content of the manuscript. All authors contributed to drafting and critically revising it and have read and approved the final submitted manuscript.

\section{FUNDING}

The Dutch Kidney Foundation (17PHD16) supported the work of AG. The Netherlands Organization for Scientific Research (NWO) as part of the Future Medicines Program (022.006.003) supported the work of KJ and CS. The authors are also grateful for the support of the Gravitation Program Materials Driven Regeneration by the Netherlands Organization for Scientific research (024.003.013).

\section{ACKNOWLEDGMENTS}

MC acknowledges the strategic alliance between University Medical Center Utrecht and Technical University Eindhoven. MC, JM, TV, and RM acknowledge the partners of Regenerative Medicine Crossing Borders (www.regmedxb.com), powered by Health Holland, Top Sector Life Sciences \& Health.

\section{SUPPLEMENTARY MATERIAL}

The Supplementary Material for this article can be found online at: https://www.frontiersin.org/articles/10.3389/fbioe. 2020.617364/full\#supplementary-material

Supplementary Figure 1 | (A) Schematic of the melt electrowriting set-up, showing the collection of thin electrified polymer jets onto a computer controlled, rotating and translating mandrel. (B) Representation of the mandrel velocities, translational $\left(V_{\text {trans }}\right)$, tangential $\left(V_{\text {tang }}\right)$, rotational $\left(V_{\text {rot }}\right)$, as well as winding angle $(\alpha)$, coil angle $(\ominus)$, tube length, pitch and mandrel perimeter $(r)$ in the mandrel surface during fiber collection. Winding angle was engineered by the ratio between $V_{\text {tang }}$ and $V_{\text {trans }}$ at constant fiber length.

Supplementary Figure 2 | Comparison between designed and printed winding angle for constructs with 1,5, and 10 stacked layers and mandrel with (A) $0.5 \mathrm{~mm}$ and (B) $3 \mathrm{~mm}$ in diameter.

Supplementary Figure 3 | (A) Tensile tester set up and (B) representative engineered stress-strain curves with determined mechanical parameters for tubular scaffolds with rhombus and random microarchitecture with cells.

Supplementary Figure $\mathbf{4}$ | Custom made perfusion system used for renal barrier function studies. MEW tubular scaffolds were mounted in a 3D printed PLA customized chamber and then perfused.

Supplementary Table 1 | Water contact angles on uncoated PCL and L-DOPA coated PCL surfaces. Mean \pm SEM, $n=3$.

Supplementary Movie 1 | Video for melt-electrowriting of tubular constructs with rhombus microstructure.

Supplementary Movie 2 | Perfusion of engineered tubules for renal barrier function testing. 


\section{REFERENCES}

Andalib, M. N., Dzenis, Y., Donahue, H. J., and Lim, J. Y. (2016). Biomimetic substrate control of cellular mechanotransduction. Biomater. Res. 20:11. doi: 10.1186/s40824-016-0059-1

Bertlein, S., Hikimoto, D., Hochleitner, G., Hummer, J., Jungst, T., Matsusaki, M., et al. (2018). Development of endothelial cell networks in 3D tissues by combination of melt electrospinning writing with cell-accumulation technology. Small. 14. doi: 10.1002/smll.201701521

Bourget, J.-M., Germain, L., Guillemette, M., and Veres, T. (2013). Alignment of Cells and Extracellular Matrix Within Tissue- Engineered Substitutes. doi: $10.5772 / 54142$

Brennan, C. M., Eichholz, K. F., and Hoey, D. A. (2019). The effect of pore size within fibrous scaffolds fabricated using melt electrowriting on human bone marrow stem cell osteogenesis. Biomed. Mater. 14:065016. doi: 10.1088/1748-605X/ab49f2

Brown, T. D., Dalton, P. D., and Hutmacher, D. W. (2011). Direct writing by way of melt electrospinning. Adv. Mater. 23, 5651-5657. doi: 10.1002/adma.201103482

Brown, T. D., Edin, F., Detta, N., Skelton, A. D., Hutmacher, D. W., and Dalton, P. D. (2014). Melt electrospinning of poly(epsilon-caprolactone) scaffolds: phenomenological observations associated with collection and direct writing. Mater. Sci. Eng. C Mater. Biol. Appl. 45, 698-708. doi: 10.1016/j.msec.2014.07.034

Caetano-Pinto, P., Janssen, M. J., Gijzen, L., Verscheijden, L., Wilmer, M. J., and Masereeuw, R. (2016). Fluorescence-based transport assays revisited in a human renal proximal tubule cell line. Mol. Pharm. 13, 933-944. doi: 10.1021/acs.molpharmaceut.5b00821

Castilho, M., Feyen, D., Flandes-Iparraguirre, M., Hochleitner, G., Groll, J., Doevendans, P. A. F., et al. (2017). Melt electrospinning writing of polyhydroxymethylglycolide-co-epsilon-caprolactone-based scaffolds for cardiac tissue engineering. Adv. Healthc. Mater. 6. doi: 10.1002/adhm.201700311

Castilho, M., Mouser, V., Chen, M., Malda, J., and Ito, K. (2019). Bi-layered microfibre reinforced hydrogels for articular cartilage regeneration. Acta Biomater. 95, 297-306. doi: 10.1016/j.actbio.2019.06.030

Castilho, M., van Mil, A., Maher, M., Metz, C. H. G., Hochleitner, G., Groll, J., et al. (2018). Melt electrowriting allows tailored microstructural and mechanical design of scaffolds to advance functional human myocardial tissue formation. Adv. Funct. Mater. 28. doi: 10.1002/adfm.201803151

Chambard, M., Gabrion, J., and Mauchamp, J. (1981). Influence of collagen gel on the orientation of epithelial cell polarity: follicle formation from isolated thyroid cells and from preformed monolayers. J Cell Biol. 91, 157-166. doi: $10.1083 /$ jcb.91.1.157

Duclos, G., Garcia, S., Yevick, H. G., and Silberzan, P. (2014). Perfect nematic order in confined monolayers of spindle-shaped cells. Soft Matter. 10, 2346-2353. doi: 10.1039/C3SM52323C

Eichholz, K. F., and Hoey, D. A. (2018). Mediating human stem cell behaviour via defined fibrous architectures by melt electrospinning writing. Acta Biomater. 75, 140-151. doi: 10.1016/j.actbio.2018.05.048

Frohlich, E. M., Alonso, J. L., Borenstein, J. T., Zhang, X., Arnaout, M. A., and Charest, J. L. (2013). Topographically-patterned porous membranes in a microfluidic device as an in vitro model of renal reabsorptive barriers. Lab Chip 13, 2311-2319. doi: 10.1039/c3lc50199j

Frohlich, E. M., Zhang, X., and Charest, J. L. (2012). The use of controlled surface topography and flow-induced shear stress to influence renal epithelial cell function. Integr. Biol. 4, 75-83. doi: 10.1039/C1IB00096A

Gasiorowski, J. Z., Liliensiek, S. J., Russell, P., Stephan, D. A., Nealey, P. F., and Murphy, C. J. (2010). Alterations in gene expression of human vascular endothelial cells associated with nanotopographic cues. Biomaterials 31, 8882-8888. doi: 10.1016/j.biomaterials.2010.08.026

Hironaka, K., Makino, H., Yamasaki, Y., and Ota, Z. (1993). Renal basement membranes by ultrahigh resolution scanning electron microscopy. Kidney Int. 43, 334-345. doi: 10.1038/ki.1993.51

Homan, K. A., Kolesky, D. B., Skylar-Scott, M. A., Herrmann, J., Obuobi, H., Moisan, A., et al. (2016). Bioprinting of 3D convoluted renal proximal tubules on perfusable chips. Sci. Rep. 6:34845. doi: 10.1038/srep34845

Hulshof, F., Schophuizen, C., Mihajlovic, M., van Blitterswijk, C., Masereeuw, R., de Boer, J., et al. (2018). New insights into the effects of biomaterial chemistry and topography on the morphology of kidney epithelial cells. J. Tissue Eng. Regen. Med. 12, e817-e27. doi: 10.1002/term.2387
Jang, K. J., Mehr, A. P., Hamilton, G. A., McPartlin, L. A., Chung, S., Suh, K. Y., et al. (2013). Human kidney proximal tubule-on-a-chip for drug transport and nephrotoxicity assessment. Integr. Biol. 5, 1119-1129. doi: 10.1039/c3ib40049b

Jansen, J., De Napoli, I. E., Fedecostante, M., Schophuizen, C. M., Chevtchik, N. V., Wilmer, M. J., et al. (2015). Human proximal tubule epithelial cells cultured on hollow fibers: living membranes that actively transport organic cations. Sci. Rep. 5:16702. doi: 10.1038/srep16702

Jansen, J., Fedecostante, M., Wilmer, M. J., Peters, J. G., Kreuser, U. M., van den Broek, P. H., et al. (2016). Bioengineered kidney tubules efficiently excrete uremic toxins. Sci. Rep. 6:26715. doi: 10.1038/srep26715

Jansen, J., Schophuizen, C. M., Wilmer, M. J., Lahham, S. H., Mutsaers, H. A., Wetzels, J. F., et al. (2014). A morphological and functional comparison of proximal tubule cell lines established from human urine and kidney tissue. Exp. Cell Res. 323, 87-99. doi: 10.1016/j.yexcr.2014.02.011

Jansen, K., Castilho, M., Aarts, S., Kaminski, M. M., Lienkamp, S. S., Pichler, R., et al. (2019). Fabrication of kidney proximal tubule grafts using biofunctionalized electrospun polymer scaffolds. Macromol. Biosci. 19:e1800412. doi: 10.1002/mabi.201800412

Jansen, K., Schuurmans, CCL, Jansen, J., Masereeuw, R., and Vermonden, T. (2017). Hydrogel-based cell therapies for kidney regeneration: current trends in biofabrication and in vivo repair. Curr. Pharm. Des. 23, 3845-3857. doi: 10.2174/1381612823666170710155726

Joly, P., Duda, G. N., Schone, M., Welzel, P. B., Freudenberg, U., Werner, C., et al. (2013). Geometry-driven cell organization determines tissue growths in scaffold pores: consequences for fibronectin organization. PLoS ONE. 8:e73545. doi: 10.1371/journal.pone.0073545

Jungst, T., Pennings, I., Schmitz, M., Rosenberg, AJWP, Groll, J., and Gawlitta, D. (2019). Heterotypic scaffold design orchestrates primary cell organization and phenotypes in cocultured small diameter vascular grafts. Adv. Funct. Mater. 29. doi: 10.1002/adfm.201905987

Kennedy, K. M., Bhaw-Luximon, A., and Jhurry, D. (2017). Cell-matrix mechanical interaction in electrospun polymeric scaffolds for tissue engineering: Implications for scaffold design and performance. Acta Biomater. 50, 41-55. doi: 10.1016/j.actbio.2016.12.034

Kim, S. O., Kim, J., Okajima, T., and Cho, N. J. (2017). Mechanical properties of paraformaldehyde-treated individual cells investigated by atomic force microscopy and scanning ion conductance microscopy. Nano Converg. 4:5. doi: 10.1186/s40580-017-0099-9

Li, X., Balagam, R., He, T. F., Lee, P. P., Igoshin, O. A., and Levine, H. (2017). On the mechanism of long-range orientational order of fibroblasts. Proc. Natl. Acad. Sci. U. S. A. 114, 8974-8979. doi: 10.1073/pnas.1707210114

Lin, NYC, Homan, K. A., Robinson, S. S., Kolesky, D. B., Duarte, N., Moisan, A., et al. (2019). Renal reabsorption in 3D vascularized proximal tubule models. Proc. Natl. Acad. Sci. U. S. A. 116, 5399-5404. doi: 10.1073/pnas.1815208116

Ling, Y., Li, C., Feng, K., Duncan, R., Eisma, R., Huang, Z., et al. (2016). Effects of fixation and preservation on tissue elastic properties measured by quantitative optical coherence elastography (OCE). J. Biomech. 49, 1009-1015. doi: 10.1016/j.jbiomech.2016.02.013

McColl, E., Groll, J., Jungst, T., and Dalton, P. D. (2018). Design and fabrication of melt electrowritten tubes using intuitive software. Mater. Design. 155, 46-58. doi: 10.1016/j.matdes.2018.05.036

Ni, M., Teo, J. C., Ibrahim, M. S., Zhang, K., Tasnim, F., Chow, P. Y., et al. (2011). Characterization of membrane materials and membrane coatings for bioreactor units of bioartificial kidneys. Biomaterials 32, 1465-1476. doi: 10.1016/j.biomaterials.2010.10.061

Oo, Z. Y., Deng, R., Hu, M., Ni, M., Kandasamy, K., bin Ibrahim, M. S., et al. (2011). The performance of primary human renal cells in hollow fiber bioreactors for bioartificial kidneys. Biomaterials 32, 8806-8815. doi: 10.1016/j.biomaterials.2011.08.030

Paxton, N. C., Daley, R., Forrestal, D. P., Allenby, M. C., and Woodruff, M. A. (2020). Auxetic tubular scaffolds via melt electrowriting. Mater. Des. 193:108787. doi: 10.1016/j.matdes.2020.108787

Pennings, I., van Haaften, E. E., Jungst, T., Bulsink, J. A., Rosenberg, A., Groll, J., et al. (2019). Layer-specific cell differentiation in bi-layered vascular grafts under flow perfusion. Biofabrication 12:015009. doi: 10.1088/1758-5090/ ab47f0

Privratsky, J. R., and Newman, P. J. (2014). PECAM-1: regulator of endothelial junctional integrity. Cell Tissue Res. 355, 607-619. doi: $10.1007 / \mathrm{s} 00441-013-1779-3$ 
RayChaudhury, A., Elkins, M., Kozien, D., and Nakada, M. T. (2001). Regulation of PECAM-1 in endothelial cells during cell growth and migration. Exp. Biol. Med. 226, 686-691. doi: 10.1177/153537020222600715

Rayner, S. G., Phong, K. T., Xue, J., Lih, D., Shankland, S. J., Kelly, E. J., et al. (2018). Reconstructing the human renal vascular-tubular unit in vitro. Adv. Healthc. Mater. 7:e1801120. doi: 10.1002/adhm.201801120

Robinson, T. M., Hutmacher, D. W., and Dalton, P. D. (2019). The next frontier in melt electrospinning: taming the jet. Adv. Funct. Mater. 29. doi: 10.1002/adfm.201904664

Saidy, N. T., Wolf, F., Bas, O., Keijdener, H., Hutmacher, D. W., Mela, P., et al. (2019). Biologically inspired scaffolds for heart valve tissue engineering via melt electrowriting. Small 15:e1900873. doi: 10.1002/smll.201900873

Sankaran, J., Uzer, G., van Wijnen, A. J., and Rubin, J. (2019). Gene regulation through dynamic actin control of nuclear structure. Exp. Biol. Med. 244, 1345-1353. doi: 10.1177/1535370219850079

Singh, N. K., Han, W., Nam, S. A., Kim, J. W., Kim, J. Y., Kim, Y. K., et al. (2020). Three-dimensional cell-printing of advanced renal tubular tissue analogue. Biomaterials 232:119734. doi: 10.1016/j.biomaterials.2019.119734

Tasnim, F., and Zink, D. (2012). Cross talk between primary human renal tubular cells and endothelial cells in cocultures. Am. J. Physiol. Renal Physiol. 302, F1055-F1062. doi: 10.1152/ajprenal.00621.2011

Tremblay, D., Andrzejewski, L., Leclerc, A., and Pelling, A. E. (2013). Actin and microtubules play distinct roles in governing the anisotropic deformation of cell nuclei in response to substrate strain. Cytoskeleton 70, 837-848. doi: $10.1002 / \mathrm{cm} .21148$

Tylek, T., Blum, C., Hrynevich, A., Schlegelmilch, K., Schilling, T., Dalton, P. D., et al. (2020). Precisely defined fiber scaffolds with 40 mum porosity induce elongation driven M2-like polarization of human macrophages. Biofabrication 12:025007. doi: 10.1088/1758-5090/ab5f4e van Genderen, A. M., Jansen, J., Cheng, C., Vermonden, T., and Masereeuw, R. (2018). Renal tubular- and vascular basement membranes and their mimicry in engineering vascularized kidney tubules. Adv. Healthc. Mater. 7:e1800529. doi: 10.1002/adhm.201800529

Vriend, J., Peters, JGP, Nieskens, TTG, Skovronova, R., Blaimschein, N., Schmidts, M., et al. (2020). Flow stimulates drug transport in a human kidney proximal tubule-on-a-chip independent of primary cilia. Biochim. Biophys. Acta Gen. Subj. 1864:129433. doi: 10.1016/j.bbagen.2019.129433

Wang, Z., Teoh, S. H., Hong, M., Luo, F., Teo, E. Y., Chan, J. K., et al. (2015). Dual-microstructured porous, anisotropic film for biomimicking of endothelial basement membrane. ACS Appl. Mater. Interfaces 7, 13445-13456. doi: 10.1021/acsami.5b02464

Weber, E. J., Chapron, A., Chapron, B. D., Voellinger, J. L., Lidberg, K. A., Yeung, C. K., et al. (2016). Development of a microphysiological model of human kidney proximal tubule function. Kidney Int. 90, 627-637. doi: 10.1016/j.kint.2016.06.011

Conflict of Interest: The authors declare that the research was conducted in the absence of any commercial or financial relationships that could be construed as a potential conflict of interest.

Copyright (c) 2021 van Genderen, Jansen, Kristen, van Duijn, Li, Schuurmans, Malda, Vermonden, Jansen, Masereeuw and Castilho. This is an open-access article distributed under the terms of the Creative Commons Attribution License (CC BY). The use, distribution or reproduction in other forums is permitted, provided the original author(s) and the copyright owner(s) are credited and that the original publication in this journal is cited, in accordance with accepted academic practice. No use, distribution or reproduction is permitted which does not comply with these terms. 